\title{
Carcinoma of Breast in Young Females A One-Year Retrospective Study
}

\author{
Abdul Hakeem Attar MD ${ }^{1}$, Mohammad S. Iqbal ${ }^{2}$
}

${ }^{1}$ Consultant Pathologist, Bahmani Diagnostic Laboratory, Bahmani Hospital, Kalaburagi, Karnataka, India

${ }^{2}$ Consultant Pathologist, Bahmani Hospital, Kalaburagi, Karnataka, India

DOI: $\underline{10.36348 / \mathrm{sjpm} .2021 . v 06 \mathrm{i} 01.003}$

| Received: 26.12.2020 | Accepted: 02.01.2021 | Published: 05.01.2021

*Corresponding author: Dr. Mohammad S. Iqbal

\section{Abstract}

Background \& Objectives: Breast cancer is the most common cancer in women and the second most common cancer worldwide. It is also the second leading cause of death due to cancer. Breast cancer is less frequent in the younger age group but have a poorer outcome in contrast to the breast cancer arising in the older age groups. There is a lack of awareness and due to this, majority of patients present late. The aim of this study is to know the incidence and clinicopathological features of breast cancer in young females under the age of 40 years. Methods: This is a retrospective study done over a period of one year at a tertiary care hospital in south India. The hospital and lab records were searched for histologically confirmed breast cancer cases in female patients under the age of 40 years. A total of 14 breast cancer cases were identified and hematoxylin and eosin stained histopathology slides were retrieved from the histopathology archives and were reviewed. The available slides of immunohistochemistry markers were also reviewed. Results: The most common histological type was infiltrating ductal carcinoma (IDC) seen in $13(92.8 \%)$ cases with 1 case of invasive lobular carcinoma. Half of cases were of stage III at the time of diagnosis. $4(28.57 \%)$ cases presented as stage II and 3 $(21.4 \%)$ cases were stage I. There was a predominance of higher grade with 7 (50\%) cases having grade II and $5(35.7 \%)$ of cases were grade III. On IHC, 4 cases $(28.57 \%)$ were negative for estrogen receptor, progesterone receptor and Her 2 neu. Conclusion: Young breast cancer patients present with higher stage, higher tumor grade and hormonal receptor negative status. More studies are needed to investigate survival and post treatment recurrence in young females with breast cancer.

Keywords: Breast cancer, Infiltrating ductal carcinoma.

Copyright () 2021 The Author(s): This is an open-access article distributed under the terms of the Creative Commons Attribution 4.0 International License (CC BY-NC 4.0) which permits unrestricted use, distribution, and reproduction in any medium for non-commercial use provided the original author and source are credited.

\section{INTRODUCTION}

Breast cancer is the most common cancer in the women and the second most common cancer worldwide [1]. It is also the second leading cause of death due to cancer [2]. Every year there are 1,00,000 new cases of breast cancer occurring in Indian women. There is a lack of awareness and due to this, majority of Indian patients present late [3]. Breast cancer is less frequent in the younger age group but have a poorer outcome in contrast to the breast cancer arising in the older age groups $[4,5]$. The proportion of breast cancer cases in young varies according to the geographical region and socioeconomic status [6]. There is a significant increase in the incidence and cancer associated morbidity and mortality in Indian subcontinent. Breast cancer in young females is more common in the metropolitan cities whereas in rural areas the incidence is low [7]. Younger women are often less likely to seek medical advise leading to a more advanced stage at the time of presentation of breast cancer [8]. The diagnosis of breast cancer in young has more implications than in the elderly women as higher mortality is associated with the younger age [9].

We undertook this retrospective study to know the incidence and clinicopathological features of breast cancer in young females under the age of 40 years.

\section{MATERIAL AND METHODS}

This is a retrospective study done over a period of one year at a tertiary care hospital in south India. The hospital and lab records were searched for histologically confirmed breast cancer cases in female patients under the age of 40 years. All other breast cancer cases in patients above 40 years of age, male breast cancer and in-situ cancers where not included. A total of 14 breast cancer cases were identified and hematoxylin and eosin stained histopathology slides were retrieved from the histopathology archives. The demographic and clinical details were recorded from the hospital files. The available slides of immunohistochemistry markers were also retrieved for 
Abdul Hakeem Attar \& Mohammad S. Iqbal; Saudi J Pathol Microbiol, Jan, 2021; 6(1): 8-12

review. The slides were reviewed by a senior histopathologist to confirm the diagnosis. The data collected includes demographics, clinical presentation and stage at the time of diagnosis. Other details like lymph node status, tumor grade, presence of lymphovascular invasion, perineural invasion, hormonal receptor and human epidermal growth factor receptor 2 (Her 2) status were also recorded and confirmed by reviewing the slides by the histopathologist.

\section{RESULTS}

There were 14 cases of breast carcinoma during the one year of study period. Majority of the cases were in the age group of 30-40 years. Two cases were reported in the age group of 20-25 years. None of the patients had a family history of breast cancer.

The tumors were equally distributed with 7 $(50 \%)$ cases in the right breast and $7(50 \%)$ in the left breast of the 14 patients. There was no bilateral disease. The most common histological type was infiltrating ductal carcinoma (IDC) seen in $13(92.8 \%)$ cases with 1 case of invasive lobular carcinoma. In this study, half of cases were of stage III at the time of diagnosis. 4 $(28.57 \%)$ cases presented as stage II and $3(21.4 \%)$ cases were stage I. None of the cases were stage IV at the time of diagnosis. There was a predominance of higher grade with 7 (50\%) of cases having grade II and $5(35.7 \%)$ of cases were grade III. Only $2(28.5 \%)$ cases were of grade I. Immunohistochemistry data for hormonal receptors and Human epidermal growth factor receptor (Her 2 neu) was not available for 4 cases. In the remaining cases, 4 cases $(28.57 \%)$ were negative for estrogen receptor, progesterone receptor and Her 2 neu (Table-1). Microscopic examination showed the characteristic histological features of infiltrating ductal carcinoma in 13 cases and one case showed features of invasive lobular carcinoma. One case of IDC showed significant desmoplasia (Figure-1).

Table-1: Demographics and characteristics of breast cancer in young females

\begin{tabular}{|c|l|}
\hline Number of cases & $\mathbf{1 4}$ \\
\hline Age Distribution (in years) & 02 \\
$21-25$ & 02 \\
$26-30$ & 06 \\
$31-35$ & 04 \\
$35-40$ & \\
\hline Histological type & $13(92.8 \%)$ \\
Infiltrating ductal carcinoma & $01(7.14 \%)$ \\
Invasive lobular carcinoma & \\
TNM Stage & $03(21.4 \%)$ \\
Stage I & $04(28.57 \%)$ \\
Stage II & $07(50 \%)$ \\
Stage III & 0 \\
Stage IV & $2(28.5 \%)$ \\
Grade & $7(50 \%)$ \\
Grade I & $5(35.7 \%)$ \\
Grade II & \\
Grade III & $2(28.5 \%)$ \\
ER Positive/PR Positive Her 2 neu Positive & $3(21.4 \%)$ \\
ER Positive/PR Positive Her 2 neu Negative & $4(28.57 \%)$ \\
ER Negative/PR Negative Her 2 neu Negative & $1(7.14 \%)$ \\
ER Positive/PR Positive Her 2 neu Positive & $4(28.57 \%)$ \\
Not Available &
\end{tabular}



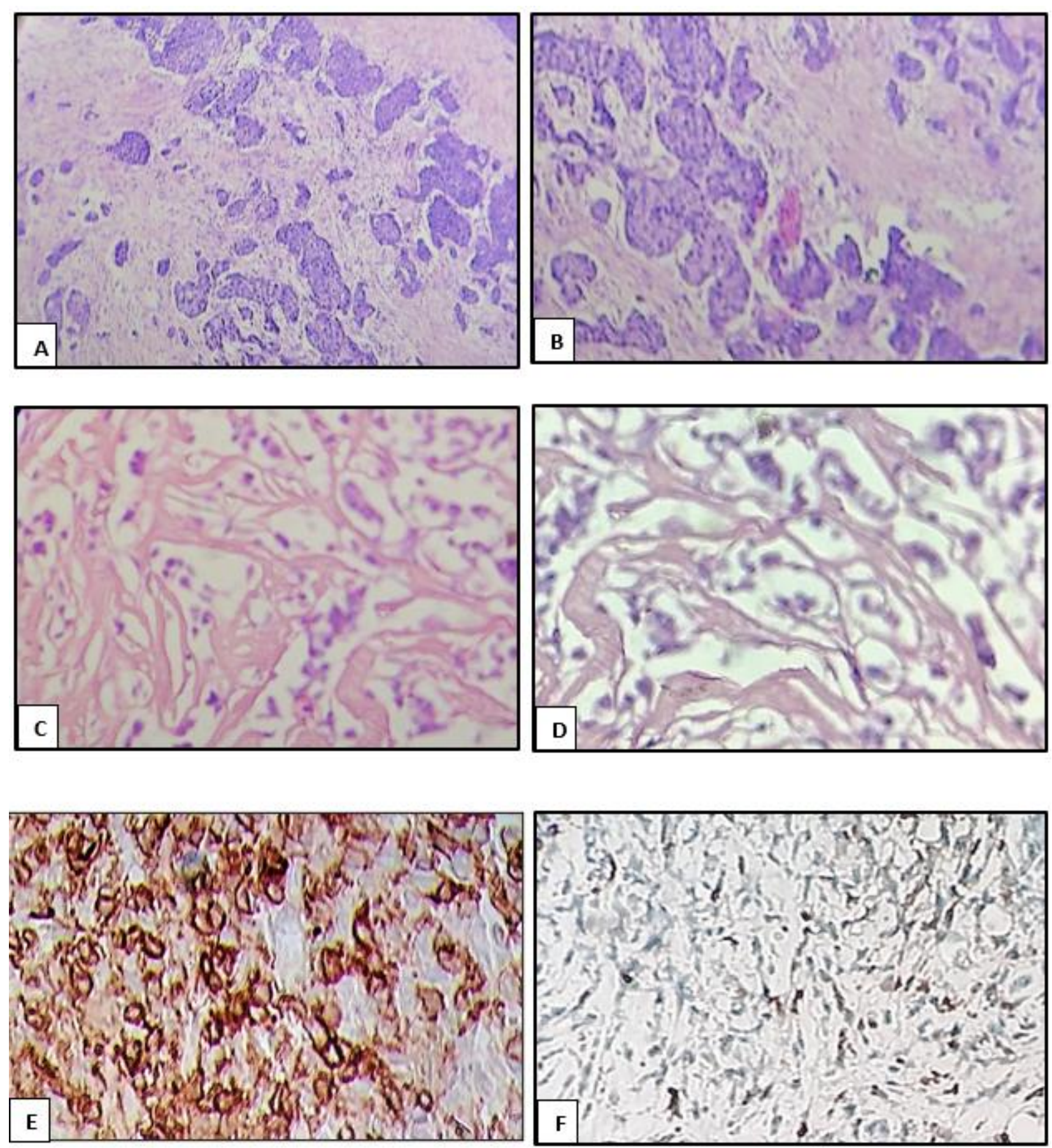

Fig-1: A. Tumor cells infiltrating the stroma $(H \&$ E, 10X); B. Tumor cells infiltrating the stroma $(H \&$ E, 20X); C and D. Tumor cells scattered in the desmoplastic stroma (H\&E, 20X); E. Her 2 neu positive tumor cells (40X); F. Her 2 neu Negative (20X)

\section{DISCUSSION}

We present here 14 histologically confirmed cases of breast carcinoma in the young female under 40 years of age. Clinically and histologically the breast cancer in the young patients are different from those reported in elderly patients. In our study, the most common histological type was infiltrating ductal carcinoma, a finding reported by other studies as well (Table-2). The predominant stage of presentation in young patients with breast cancer was stage III, a finding also reported by others [3, 8, 10-14].
There is an increase in prevalence of female breast cancer in young patients in India and is more likely to present at higher stage and grade. Genome wide association studies have identified numerous single nucleotide polymorphism that are associated with an increased risk of breast cancer [15]. Tumors in young patients are more endocrine unresponsive [16]. The main factors associated with breast cancer development in young women would be hormonal and reproductive status [17] 
Abdul Hakeem Attar \& Mohammad S. Iqbal; Saudi J Pathol Microbiol, Jan, 2021; 6(1): 8-12

Table-2: Comparison of breast cancer characteristics in young females

\begin{tabular}{|c|c|c|c|c|}
\hline Study & $\begin{array}{l}\text { Number of cases }<40 \\
\text { year) }\end{array}$ & $\begin{array}{l}\text { Most common } \\
\text { histological type }\end{array}$ & $\begin{array}{l}\text { Predominant TNM } \\
\text { Stage }\end{array}$ & Grade \\
\hline Present study & 14 & $\begin{array}{l}\text { IDC } \\
13(92.8 \%)\end{array}$ & $\begin{array}{l}\text { Stage III } \\
7(50 \%)\end{array}$ & $\begin{array}{l}\text { Grade II } \\
7(50 \%)\end{array}$ \\
\hline $\begin{array}{l}\text { Bakkach J et al., } \\
{[10]}\end{array}$ & 82 & $\begin{array}{l}\text { IDC } \\
95.2 \%\end{array}$ & $\begin{array}{l}\text { Stage II } \\
65.8 \%\end{array}$ & $\begin{array}{l}\text { Grade II } \\
47.6 \%\end{array}$ \\
\hline $\begin{array}{l}\text { Zimmer AS et al., } \\
\text { [11] }\end{array}$ & 1139 & Not available & $\begin{array}{l}\text { Stage II } \\
45.4 \%\end{array}$ & $\begin{array}{l}\text { Grade III } \\
49.5 \%\end{array}$ \\
\hline Wang K et al., [12] & 2682 & Not available & $\begin{array}{l}\text { Stage II } \\
31.92 \%\end{array}$ & $\begin{array}{l}\text { Grade II } \\
26.88 \%\end{array}$ \\
\hline Thapa et al., [8] & 263 & $\begin{array}{l}\text { IDC } \\
93.1 \% \\
\end{array}$ & $\begin{array}{l}\text { Stage III } \\
55.1 \%\end{array}$ & $\begin{array}{l}\text { Grade II/III } \\
55.9 \%\end{array}$ \\
\hline $\begin{array}{l}\text { Manilal B et al., } \\
\text { [3] }\end{array}$ & 100 & $\begin{array}{l}\text { IDC } \\
87 \%\end{array}$ & $\begin{array}{l}\text { Stage III } \\
54.8 \%\end{array}$ & $\begin{array}{l}\text { Grade III } \\
43 \%\end{array}$ \\
\hline Sivakumar P [13] & 47 & $\begin{array}{l}\text { IDC } \\
93.61 \%\end{array}$ & $\begin{array}{l}\text { Stage III } \\
53.19 \%\end{array}$ & $\begin{array}{l}\text { Not } \\
\text { available }\end{array}$ \\
\hline Thangjam S [14] & 160 & $\begin{array}{l}\text { IDC } \\
85.62 \%\end{array}$ & $\begin{array}{l}\text { Stage III } \\
47 \%\end{array}$ & $\begin{array}{l}\text { Not } \\
\text { available }\end{array}$ \\
\hline
\end{tabular}

Breast cancer is the most common malignancy among females in developed countries and $12 \%$ of the carcinoma are reported to arise in the age group of 2034 years [13]. Delay in diagnosis is one of the challenges in managing breast cancer in young patients. Infiltrating ductal carcinoma is the most common histological type reported in young patients. Poor histological grade with presence of necrosis has shown to be having a worse prognosis in young women [13]. Young females also has a greater incidence due to their carrying of BRCA1 and BRCA2 in germline and which has established the biologic basis of disease related to young age. The important prognostic factors includes tumor size, lymph node status, hormone receptor and Her 2 neu status as well as histological grade. Breast cancer in young is hormone receptor negative when compared to the breast cancer in older patients [18]. There is a possibility that in future, the younger age group breast cancer patients will be separated as a distinct category of breast cancer. Our findings are similar to the almost universal reported findings of a worse prognosis for young breast cancer patients with higher stage, higher tumor grade and hormonal receptor negative tumors [11].

Modified lifestyle and westernization has been reported as a reason for increasing trend of breast cancer in young. In India, the incidence of breast cancer in young females under the age of 35 has been reported to be ranging from $5.5 \%$ to $11.3 \%$. Breast cancer shows irregularities in between the developed and developing countries with higher incidence reported in developed countries but a higher mortality rates in developing countries. Younger age breast cancer is associated with a large sized tumor, higher number of metastatic lymph nodes, higher grade and poorer outcome [2]. Hence there is necessity to detect this at an early age.

\section{CONCLUSION}

Educating the young adults about breast cancer, organizing breast cancer detection camps can help in creating awareness of the disease. Analysis should be done for other genetic biomarkers to explain the high prevalence of breast cancer in young women. There is a need to identify molecular subtypes of breast cancer and their risk factors in young Indian women in order to develop targeted strategies for prevention and control. We recommend to start breast cancer screening at an early age. More studies are needed to investigate survival and post treatment recurrence in young females with breast cancer.

\section{Acknowledgement: Nil}

\section{Conflict of Interest: Nil}

\section{REFERENCES}

1. Fabiano, V., Mandó, P., Rizzo, M., Ponce, C., Coló, F., Loza, M., ... \& Nervo, A. (2020). Breast Cancer in Young Women Presents With More Aggressive Pathologic Characteristics: Retrospective Analysis From an Argentine National Database. JCO Global Oncology, 6, 639. 646.

2. Kumar, M. B. V., Jagdishwar, G., \& Harika, T. (2017). Breast Cancer- Rising Trend in Young! Global Journal of Surgery. 5(1): 6-8.

3. Manilal, B., Bhargavi, D., Patnayak, R., Jena, A., Reddy, K. S., Sampath, V., ... \& Manickavasagam, R. S. S. (2016). Breast cancer in young: experience at a tertiary care centre in Tirupati, Andhra Pradesh. J Clin Sci Res, 5, 93-100.

4. Das, P., Khuntia, P. K., Das, R., \& Nayyar, A. S. (2020). A Retrospective Clinico-pathologic Analysis of 100 Breast Cancer Cases: Experience from a Tertiary Care Hospital of Coastal 
Abdul Hakeem Attar \& Mohammad S. Iqbal; Saudi J Pathol Microbiol, Jan, 2021; 6(1): 8-12

India. International Journal of Medicine and Public Health, 10(2), 81-84.

5. Shah, A. N., Metzger, O., Bartlett, C. H., Liu, Y., Huang, X., \& Cristofanilli, M. (2020). Hormone Receptor-Positive/Human Epidermal Growth Receptor 2-Negative Metastatic Breast Cancer in Young Women: Emerging Data in the Era of Molecularly Targeted Agents. The oncologist, 25(6), e900-e908.

6. Romieu, I., Biessy, C., Torres-Mejía, G., ÁngelesLlerenas, A., Sánchez, G. I., Borrero, M., ... \& Garmendia, M. L. (2020). Project profile: a multicenter study on breast cancer in young women in Latin America (PRECAMA study). salud pública de méxico, 61, 601-608.

7. Malvia, S., Bagadi, S. A., Dubey, U. S., \& Saxena, S. (2017). Epidemiology of breast cancer in Indian women. Asia-Pacific Journal of Clinical Oncology, 13(4), 289-295.

8. Thapa, B., Singh, Y., Sayami, P., Shrestha, U. K., Sapkota, R., \& Sayami, G. (2013). Breast cancer in young women from a low risk population in Nepal. Asian Pac J Cancer Prev, 14(9), 50955099.

9. Ntekim, A., Nufu, F. T., \& Campbell, O. B. (2009). Breast cancer in young women in Ibadan, Nigeria. African health sciences, 9(4):242-246.

10. Bakkach, J., Mansouri, M., Derkaoui, T., Loudiyi, A., Fihri, M., Hassani, S., ... \& Mechita, M. B. (2017). Clinicopathologic and prognostic features of breast cancer in young women: a series from North of Morocco. BMC women's health, 17(1), 106.

11. Zimmer, A. S., Zhu, K., Steeg, P. S., Wu, A., Gatti-Mays, M. E., Soltani, S., ... \& Hu, H. (2018). Analysis of breast cancer in young women in the Department of Defense (DOD) database. Breast cancer research and treatment, 168(2), 501-511.

12. Wang, K., Ren, Y., Li, H., Zheng, K., Jiang, J., Zou, T., ... \& Wang, L. (2016). Comparison of clinicopathological features and treatments between young ( $\leq 40$ years) and older ( $>40$ years) female breast cancer patients in West China: a retrospective, epidemiological, multicenter, case only study. PloS one, 11(3), e0152312.

13. Sivakumar, P., Ravi, C., \& Rodrigues, G. (2015). Breast cancer in young women: The effect of age on tumor biology and prognosis. Clinical Cancer Investigation Journal, 4(2), 165-169.

14. Thangjam, S., Laishram, R. S., \& Debnath, K. (2014). Breast carcinoma in young females below the age of 40 years: A histopathological perspective. South Asian journal of cancer, 3(2), 97-100.

15. Rath, M., Li, Q., Li, H., Lindström, S., Miron, A., Miron, P., ... \& Seo, J. H. (2019). Evaluation of significant genome-wide association studies riskSNPs in young breast cancer patients. PloS one, 14(5), e0216997.

16. Kataoka, A., Tokunaga, E., Masuda, N., Shien, T., Kawabata, K., \& Miyashita, M. (2014). Clinicopathological features of young patients (< 35 years of age) with breast cancer in a Japanese Breast Cancer Society supported study. Breast cancer, 21(6), 643-650.

17. Slaoui, M., Mouh, F. Z., Ghanname, I., Razine, R., El Mzibri, M., \& Amrani, M. (2016). Outcome of breast cancer in Moroccan young women correlated to clinic-pathological features, risk factors and treatment: a comparative study of 716 cases in a single institution. PLoS One, 11(10), e0164841.

18. Kroman, N., Tutt, A., Jensen, M. B., Wohlfahrt, J., Mouridsen, H. T., Andersen, P. K., ... \& Ross, G. (2000). Factors influencing the effect of age on prognosis in breast cancer: population based studyCommentary: much still to learn about relations between tumour biology, prognosis, and treatment outcome in early breast cancer. Bmj, 320(7233), 474-479. 